\section{FRI0150 CLINICAL MANIFESTATIONS OF GIANT CELL ARTERITIS: CHANGES OVER 20 YEARS}

${ }^{1} \mathrm{KT}$ Calamia, ${ }^{2} \mathrm{JR}$ Basarich, ${ }^{3} \mathrm{M}$ Schirmer, ${ }^{1} \mathrm{MD}$ Cohen. ${ }^{1}$ Rheumatology, Mayo Clinic, Jacksonville, USA; ${ }^{2}$ Medical Student, Medical College of Wisconsin, Milwaukee, USA; 3 Internal Medicine, Innsbruck University, Innsbruck, Austria

10.1136/annrheumdis-2001.210

Background Complications of Giant Cell Arteritis (GCA) can be prevented with prompt diagnosis and treatment in most cases. However, the presenting manifestations of the disease are diverse and may be non-specific.

Objectives We undertook this study in order to determine the clinical features in 100 conecutive patients with GCA. We compared these features in patients with and without visual loss. We compared the findings to those from a study of 100 consecutive biopsy proven cases from the same institution by one of the authors (KTC) 20 years earlier.

Methods We reviewed the clinical records of 100 consecutive biopsy-proven cases of GCA diagnosed just prior to December 31, 1998. Findings in patients with and without visual loss were compared and findings in this series were compared to those of an identical review of 100 consecutive biopsy-proven cases from our institution, ending in December, 1978. ${ }^{1}$ Differences were compared using Fisher's exact test and the rank sum test.

Results In the current series, there were 77 females and 23 males, with a mean age at diagnosis of 73.2 years. The mean duration of symptoms prior to diagnosis was 3.5 months. Headache was the initial symptom in 41 patients and twenty patients presented with polymyalgia rheumatica. However, systemic symptoms dominated the clinical presentation in 22 patients and 13 patients were evaluated for fever of unknown origin. Swallowing or tongue claudication was seen in 7 patients. Trismus or dysgeusia were reported by some patients. Nine patients complained of sore throat and 10 patients had cough. Twelve patients developed loss of vision. Inflammatory parameters were not significantly different in patients with visual loss as compared to those without. The median duration of symptoms were shorter $(p<0.001)$, median sedimentation rate was lower $(p<$ $0.001)$ and the median haemoglobin concentration was higher ( $p$ $=0.011)$ in the current series when compared to patients diagnosed 20 years earlier.

Conclusion The presenting manifestations in this group of patients with GCA were diverse and often did not suggest the diagnosis. Clinical suspicion for the disease in the setting of an older patient with systemic symptoms or with a variety of head and neck symptoms, with laboratory evidence of an inflammatory process, was critical for the diagnosis. Because of this suspicion, patients were diagnosed earlier after onset of symptoms, with less prominent inflammatory findings, than they were 20 years ago.

\section{REFERENCE}

1 Calamia KT, Hunder GG. Clinical manifestations of giant cell (temporal) arteritis. Clin Rheum Dis. 1980;6:389-403

\section{FRI0151 BCL-2 LEVELS OF PERIPHERAL MONONUCLEAR CELLS IN PATIENTS WITH BEHCET'S DISEASE}

HT Ozer, E Erken, R Gunesacar. Rheumatology-Immunology, Cukurova University Medical School, Adana, Turkey

10.1136/annrheumdis-2001.211
Background Apoptosis is strictly programmed cell death of aged, disrupted or unnecessary cells. It has substantial role in the development and control of immune system. Its dysregulation may play a part in the pathogenesis of autoimmune disorders. $\mathrm{Bcl}-2$ is an protooncogen of controlling apoptosis in immunocompetent cells.

Objectives Bcl-2 levels of peripheral mononuclear cells in patients with Behcet's disease were investigated in order to have information about the apoptotic processes of this vasculitis which pathogenesis is unknown.

Methods Twenty-eight Behcet's (mean age \pm SD, $41.9 \pm 7.8 ; 15$ male,13 female), 21 familial Mediterranean fever (FMF), (mean age $34.5 \pm 12.4 ; 9$ male, 12 female), 11 rheumatoid arthritis (RA) patients (mean age $44.9 \pm 18.5 ; 1$ male, 10 female) and 22 controls (mean age $37.7 \pm 6.9 ; 11$ male, 11 female) were taken into the study. Peripheral mononuclear cells of the subjects were isolated by phicol gradient method; after cell counts were standardised according to the kit instructions, the cells were lysed and Bcl-2 levels were studied by ELISA method.

Results Mean Bcl-2 levels of the Behcet's patients (mean \pm SEM, $78.58 \pm 16.38 \mathrm{U} / \mathrm{ml}$ ) were found significantly lower than that of the controls $(161.70 \pm 23.97 \mathrm{U} / \mathrm{ml}),(\mathrm{p}=0.006)$. No difference was found between the mean Bcl-2 levels of the active and inactive Behcet's patients. The mean Bcl-2 level of Behcet group was not significantly different than those of the FMF $(112.97 \pm 29.97 \mathrm{U} / \mathrm{ml})$ and the RA $(82.63 \pm 31.87 \mathrm{U} / \mathrm{ml})$ groups. Mean Bcl-2 levels of the FMF $(\mathrm{p}=0.061)$ and the RA $(p=0.076)$ groups were also not different than that of the controls.

Conclusion Low levels of Bcl-2 in peripheral mononuclear cells of Behcet's patients might be a clue to the dysregulation of programmed cell death in mononuclear cells of this vasculitis.

\section{FRI0152 CRIYOGLOBULINEMIA IN HEPATITIS C INFECTIVE HEMODIALYSIS AND RENAL TRANSPLANTATION PATIENTS}

E Dalkilic, M Gullulu, G Karadogan, M Yavuz, K Dilek, A Ersoy, M Yurtkuran. Rheumatology, Uludag University Medical Faculty, Bursa, Turkey

\subsection{6/annrheumdis-2001.212}

Background Hepatitis C infection (HCV) is an important problem among hemodialysis and renal transplantation patients. It has been showed that HCV infection is closely associated with mixed type criyoglobulinemia, despite this close relationship, the correlation of HCV and essential mixed criyoglobulinemia has been analysed in a very limited number of studies in hemodialysed and renal transplant patients.

Objectives In this study, we aimed to investigate the prevalence of criyoglobulinemia in HCV positive hemodialysis patients, renal transplant patients and in patients with chronic liver disease in Turkey which type I HCV is the dominant form.

Methods Criyoglobulinemia was studied in 41 hemodialysis, 10 renal transplant and 17 chronic liver disease patients with $\mathrm{HCV}$ infection. Anti-HCV antibodies were detected by second and third generation ELISA and for criyoglobulins centrifugation and cold incubation techniques were used.

Results None of the HCV positive hemodialysis and renal transplant patients were found to have criyoglobulinemia, on the other hand criyoglobulinemia was present in only one patient with HCV positive chronic liver disease. 
Conclusion Type I HCV is the most common hepatitis $\mathrm{C}$ virus type in our hemodialysis unit and in Turkey, so this low prevalence of criyoglobulinemia may be associated with the genotype of $\mathrm{HCV}$ and the differences of the geographic areas.

\section{FRI0153 CARDIOVASCULAR AUTONOMIC FUNCTIONS AND SYMPATHETIC SKIN RESPONSES IN BEHÇET'S DISEASE}

K Aksu, Z Colakoglu, G Keser, N Kýglýoglu, V Inal, G Gumusdýs, E Doganavsargýl. Rheumatology, Ege University Faculty of Medicine, Izmir, Turkey

\subsection{6/annrheumdis-2001.213}

Background Unlike other systemic necrotizing vasculitides, such as periarteritis nodosa and Churg-Strauss Syndrome, peripheral and autonomic nervous system involvement is rare Behçet's disease.

Objectives We examined the peripheral nervous system involvement, cardiovascular autonomic functions and sympathetic skin responses in Behçet's patients.

Methods Fifteen age and sex matched healthy controls, besides 26 Behçet's patients were included in this study. In order to exclude the effects of colchicine an the parameters tested, 16 patients with familial mediterranean fever (FMF) were also studied. In addition to electromyographic studies and sympathetic skin potentials, variations of R-R interval in electrocardiograhpy in response to hyperventilation and Valsalva manoeuvre were recorded. Patients with disorders that may cause autonomic dysfunction were excluded from the study.

Results There was no difference among the three groups in evaluations performed during hyperventilation and Valsalva manoeuvres. No pathologic electromyographic finding was recorded except the sensory motor polyneuropathy detected in a single Behçet's patient. The amplitude and latencies of skin potentials obtained in Behcet's patients were not significantly different when compared with healthy controls and FMF patients. Colchicine usage did not significantly alter the electrophysiological measurements in Behcet's and FMF patients.

Conclusion There was no evidence of peripheral autonomic nervous system involvement in Behçet's disease. We conclude that autonomic nervous system involvement is not significant in Behçet's disease.

\section{FRI0154 LEFLUNOMIDE IN A PATIENT WITH GLUCOCORTICOID- AND METHOTREXAT- RESISTANT TAKAYASU?S ARTERITIS}

${ }^{1} \mathrm{G}$ Haberhauer, ${ }^{1} \mathrm{~J}$ Feyertag, ${ }^{2} \mathrm{EM}$ Kittl, ${ }^{2} \mathrm{~K}$ Bauer, ${ }^{1} \mathrm{~A}$ Dunky. ${ }^{1} 5$ th Department of Internal Medicine (Rheumatology), Wilhelminen-Hospital; ${ }^{2}$ Central-Laboratory, Danube-Hospital, Vienna, Austria

10.1136/annrheumdis-2001.214

Background Takayasu's arteritis (TA) is a chronic inflammatory large-vessel vasculitis of unknown cause, which involves the aorta and its major branches. Glucocorticosteroids (GC) and methotrexat (MTX) are the primary treatment to reduce the activity of vascular inflammation in TA. A subset of TA patients $(<15 \%)$ has chronic, unremittive disease and is unresponsive to GC + MTX therapy. Herein we describe our benefit experience with Leflunomide (LEFLU) therapy in patient with GC- and MTX-resistant TA.
Objectives Case Report: A 28-year old Turkish female with (biopsy proved) TA, markedly elevated ESR of $96 \mathrm{~mm} / \mathrm{h}$, and elevated C-reactive protein (CRP) $73 \mathrm{mg} / \mathrm{dl}$ (normal

Postoperative, after 6 month, MTX therapy was withdrawn and replaced by LEFLU ( $30 \mathrm{mg} /$ day). Within the next 2 month GC was slowly tappered to $2 \mathrm{mg} /$ day and then withdrawn.

Six month after initiating LEFLU therapy, ESR $(22 \mathrm{~mm} / \mathrm{h})$, CRP $(12 \mathrm{mg} / \mathrm{dl})$, SAA $(8 \mathrm{mg} / \mathrm{dl})$ and IL-6 $(16 \mathrm{pg} / \mathrm{ml})$ significantly decreased near to normal ranges. Even sCD44v5 decreased to 9 $\mathrm{ng} / \mathrm{ml}$.

Blood pressure measurements were now $110 / 70 \mathrm{mmHg}$ in the right arm, 90/55 $\mathrm{mmHg}$ in the left arm and radial pulses were palpable in both arms. The patient reported no syncopes, headache or any limitations of activities of daily living. ESR, CRP, SAA, IL-6 and sCD44v5 still remained in the last mentioned low ranges during the next two month of observation.

Methods "*”"

Results “*”

Conclusion In this case of GC+MTX resistant TA, LEFLU appears to be an effective (slow acting) and well tolerated agent to reduce the activity of inflammation. Extensive and long-term studies will be required to assess our single observation.

\section{FRI0155 DIFFERENT SCHEMES OF CONSERVATIVE THERAPY IN PATIENTS WITH THROMBANGIITIS OBLITERANS}

MS Gurieva, AA Baranov, SV Bagrakova, PV Shiryaev, AA Kurdjukov. Internal Medicine, Medical Academy, Yaroslavl, Russia

10.1136/annrheumdis-2001.215

\section{Background}

Objectives To compare changes of the Birmingham vasculitis activity score (BVAS) and some laboratory parameters in thrombangiitis obliterans patients (pts) treated with antiplatelet agents and vasodilators in usual doses (first group) and with standard three-days scheme glucocorticoid and cyclophosphamide pulsetherapy (second group).

Methods The first group included 12 male (mean age $37.9 \pm$ 6.9 years) and the other one - 16 male (mean age $41.3 \pm 7.5$ years). Duration of disease and clinical symptoms before the treatment were comparable in both groups, excepting the frequency of joints pain $\left(\mathrm{n} 1=41.7 \%\right.$ v.s. $\mathrm{n}^{2}=6.3 \% ; \mathrm{p}<0.05$ ) and migratory superficial phlebitis $\left(\mathrm{n} 1=66.7 \%\right.$ v.s. $\mathrm{n}^{2}=$ $18.8 \% ; \mathrm{p}<0.05$ ), which were observed significantly more often in pts of the first group. Inspection of the pts was carried out before treatment and in a month. An estimation of clinical activity has carried out on BVAS. Serum levels of C-reactive protein (CRP) by ELISA and ESR at the same time were determinated as well.

Results Before the start of treatment there were no significant differences in values of BVAS (8.2 \pm 3.5 -first group; $8.4 \pm 3.2$ - second group), ESR and CRP between both groups. In a month BVAS was significantly lower in pts of the second group, then in the first one $(6.8 \pm 3.3$ - first group v.s. $3.9 \pm 1.7-$ second group; $\mathrm{p}<0.05)$. The mean values of CRP were not significantly changes during follow-up in both groups, but high serum levels of CRP were founded significantly more often in pts of the first group then in the second after the treatment $(\mathrm{n} 1=$ $58.3 \% ; \mathrm{n}^{2}=56.3 \%$ - before; $\mathrm{n} 1=66.7 \% ; \mathrm{n}^{2}=18.8 \% ; \mathrm{p}<$ 0.05 - after the treatment, respectively). The similar features were observed for the frequency of amputations ( $\mathrm{n} 1=58.33 \%$ v.s. $\left.\mathrm{n}^{2}=12.5 \% ; \mathrm{p}<0.05\right)$. 